\title{
Characteristics of deformation of saturated soft clay under the load of Shanghai subway line No. 2
}

\author{
Yi-qun Tang $\cdot$ Ping Yang $\cdot$ Shu-kai Zhao $\cdot$ \\ Xi Zhang $\cdot$ Jian-xiu Wang
}

Published online: 6 December 2007

(C) Springer-Verlag 2007

\section{Erratum to: Environ Geol}

DOI 10.1007/s00254-007-0902-8

The original version of this article unfortunately contained an error in the author's line. Yi-qun Tang is treated as corresponding author and corresponding details are given below.

Yi-qun Tang ( $\bigotimes)$

Department of Geotechnical Engineering

Tongji University

Shanghai 200092

People's Republic of China

Key Laboratory of Geotechnical and Underground

Engineering of Ministry of Education

Tongji University

Shanghai 200092

People's Republic of China

e-mail:tangyiqun2@mail.tongji.edu.cn

The online version of the original article can be found under doi: 10.1007/s00254-007-0902-8.

Y. Tang $(\bowtie) \cdot$ P. Yang $\cdot$ J. Wang

Key Laboratory of Geotechnical and Underground Engineering of Ministry of Education, Tongji University,

Shanghai 200092, People's Republic of China

e-mail: tangyiqun2@mail.tongji.edu.cn

Y. Tang $\cdot$ P. Yang $\cdot$ S. Zhao $\cdot$ X. Zhang $\cdot$ J. Wang

Department of Geotechnical Engineering, Tongji University,

Shanghai 200092, People's Republic of China

Y. Tang

United Research Center for Urban Environment and Sustainable

Development, The Ministry of Education,

Beijing 200065, People's Republic of China 